\title{
The Stressed State Simulation of the Fixed Stepping Stoppers for the Auger Machine's Cyclic Feeding Mechanism
}

\author{
Alexey Khoreshok ${ }^{1}$, Leonid Mametyev ${ }^{1}$, Oleg Lyubimov ${ }^{2,}{ }^{*}$, Lyudmila Samorodova ${ }^{3}$, and \\ Oksana Alitkina ${ }^{1}$ \\ ${ }^{1}$ T.F. Gorbachev Kuzbass State Technical University, Department of Mining Machines and \\ Complexes, 650000 Kemerovo, 28 Vesennya st., Russian Federation \\ ${ }^{2}$ T.F. Gorbachev Kuzbass State Technical University, Department of Information and Automated \\ Production Systems, 650000 Kemerovo, 28 Vesennya st., Russian Federation \\ ${ }^{3}$ T.F. Gorbachev Kuzbass State Technical University, Department of Economics, 650000 Kemerovo, \\ 28 Vesennya st., Russian Federation
}

\begin{abstract}
The article explains the importance of auger technology in mining and underground building. The contribution of the Siberian region to the development of methods for sinking of the horizontal and slightly deviated holes is noted. The modern problems facing the developers of auger complexes are formulated. The prerequisites, methods and results of studies conducted at the Kuzbass State Technical University (KuzSTU) are given. The result of it is the possibility of flexible refinement of the complex's configuration for specific boring conditions with the verification of each applied technical solution by computer simulation. Design changes are outlined, the consequences of which can be taken into account in the near future for the auger complex's development.
\end{abstract}

\section{Introduction}

The experience of using auger transportation of bored face destruction products during sinking and mining informationally dates back to the late 20 s - early 30 s of the 20th century, when the first tons of coal were mined in the US mines in this way [1], and the auger horizontal boring device driven by the tractor power aggregate, using it to implement the axial feed force to the face, was patented [2].

Undoubtedly, over decades of development, auger technologies, along with alternative methods of boring horizontal and slightly deviated holes (puncture, punching, horizontal directional drilling, microtunneling), have been widely developed both abroad [3, 4], and in Russia. The Siberian region is no exception, where scientists from a number of scientific organizations and universities are developing and modernizing equipment for the effective implementation of the above methods. So, at the Kuzbass State Technical University, a twostage method of boring holes of the diameter required for a wide range of industrial needs is

\footnotetext{
*Corresponding author: oleglyub@gmail.com
} 
being developed, which consists in preliminary boring a small diameter pioneer hole in a direct motion with its subsequent boring to the required diameter in a reverse motion.

At the same time, the modern period puts a number of actual tasks for developers of auger complexes, including:

- an expanding the the range of physical and mechanical characteristics of the rocks and soils under development and the diameter of the conducted holes for various purposes at the same time with reducing the energy intensity of the processes [5-10];

- an effective combination of tools with various methods of destruction of the face and devices for equipment's feeding to the face using various physical principles [11-13];

- the creation of an aggregate-modular gamma of sinking equipment with a new technical level, formed according to an open principle, with the possibility of flexible refinement of the configuration of complexes for specific boring conditions with the verification of each applied technical solution by computer modeling, which affects the economic component of each project [14-16];

- a complex increase in the automation level of boring operations, operations to remove of developed boring products to the edge of the pit, operations for mounting and dismaunting of sections of the auger bore string and casing strings during direct and reverse boring, and, as a result, the development of geotechnical robotic systems that allow unmanned horizontal auger sinking of horizontal and slightly deviated holes.

Joint work to solve the last two problems is currently being actively carried out at the departments of mining machines and complexes and information and automated production systems of KuzSTU with the involvement of information from related fields of knowledge [17].

\section{Theory of the question}

Analysis and comparative evaluation of the used composition schemes preceded the work on the creation at KuzSTU of a complex of the new technical level's auger equipment. Coexisting basic circuit solutions for sinking of horizontal and slightly deviated holess are presented in fig. 1.

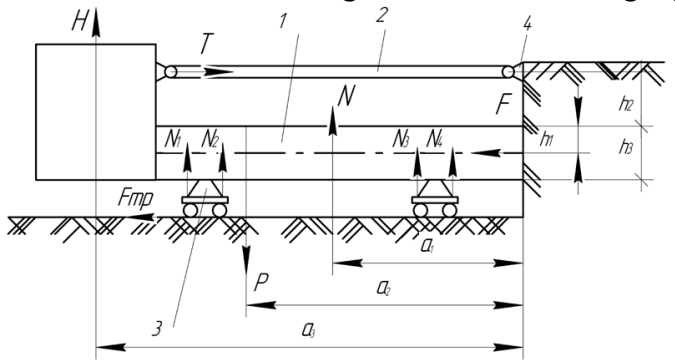

a

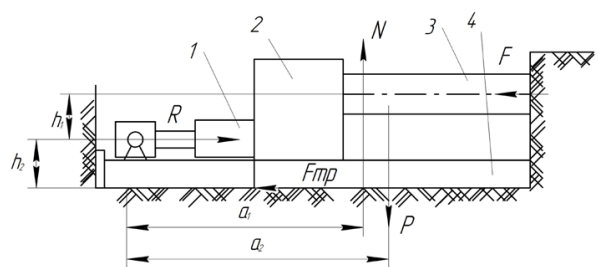

$\mathrm{b}$

Fig. 1. The main circuit solutions: a - composition diagram of the auger equipment, fed to the face on a flexible suspension, 1 - an auger stand; 2 - ropes of the traction winch; 3 - running carriage; 4 reference node; $b$ - composition diagram of the auger equipment supplied to the face on a rigid frame, 1 - jacking unit; 2 - feed mechanism; 3 - boring rig; 4 - frame.

On fig. 1, a, a diagram of an implementation of the auger equipment fed to the face on a flexible suspension is presented.

Taking into account the object of study as a solid body, moving at a constant speed $\mathrm{v}=$ const, without elasticity, the system of equations of static equilibrium looks as follows:

$$
\begin{gathered}
P \cdot a_{2}-N \cdot a_{1}-H \cdot a_{3}-F \cdot h_{1}-T \cdot h_{2}-F_{m p} \cdot h_{3}=0 ; \\
N+H-P=0 ;
\end{gathered}
$$




$$
T-F-F_{m p}=0,
$$

where $P$ is the weight of the auger equipment; $N$ is the resultant reaction of the support surface; $H$ is the holding force of the pipe-laying crane; $F$ is the reaction of the face; $T$ is the traction force of the feeding mechanism; $F_{m p}$ is the friction force of the wheels of the running carriage along the support; $a_{1}, a_{2}, a_{3}, h_{1}, h_{2}, h_{3}$ are the distances from the points of application of forces, respectively: $N, P, H, F, T, F_{m p}$ to the point of possible rotation of the device $O$.

From the first equation of system (1) it follows that the forces $T$ and $F$ that are not coaxially generated create a torque relative to point $O$. The quantities $F, F_{m p}, N, a_{l}$ are unknown in the system. The reaction of the earth's surface (support) is determined by the expression:

$$
N=P-H \text {. }
$$

The friction force is $F_{m p}=f \cdot N$, where $f$ is the coefficient of friction.

The reaction of the face will be determined by the expression:

$$
F=T-F_{m p}
$$

From (1) we define the shoulder $a_{l}$ :

$$
a_{1}=\left(P \cdot a_{2}-H \cdot a_{3}-F \cdot h_{1}-T \cdot h_{2}-F_{m p} \cdot h_{3}\right) / N .
$$

An analysis of system (1) shows that with an increase in any of the quantities $H, T, a_{3}$, the reaction of the face $F$ increases, which leads to the possibility of an imbalance, when:

$$
P \cdot a_{2}<N \cdot a_{1}+H \cdot a_{3}+F \cdot h_{1}+T \cdot h_{2}+F_{m p} \cdot h_{3}
$$

Physically, this inequality means the following: flexible connection lifts the rotator drive upward, while the auger stand goes downward accordingly, the direction of the hole changes from horizontal to inclined. In addition, the construction operating in a "suspended" state has greater instability than when the carriages support on the surface, which can lead to the departure of the stand away from the given boring axis and the appearance of large elastic forces in the auger stand, flexible connections, etc. The above factors are undesirable for ensuring the stability of auger equipment, the practical impossibility of synchronizing the operation of a complex of auger machines is generated, therefore, this circuit is unacceptable for creating equipment of a new technical level. In addition, the boring of horizontal and slightly deviated holes with equipment built according to this circuit is possible only by a direct course.

For the circuit of the auger equipment fed to the face on a rigid frame (fig. 1, b), we reduce the equations of static equilibrium to the system:

$$
\begin{gathered}
N \cdot a_{1}-P \cdot a_{2}+F \cdot h_{1}+R \cdot h_{2}-F_{m p} \cdot h_{3}=0 \\
N-P=0 ; \\
R-F-F_{m p}=0,
\end{gathered}
$$

where $R$ is the reaction of the supporting wall to the feed force.

The solution to system (6) is similar to the solution to system (1). The location of the forces $F$ and $R$ in this case is also misaligned, the distance between the axes $H=h_{1}-h_{2} \neq 0$. This leads to the appearance of torques, the ratio of which characterizes the first equation of system (6). For the center of rotation, you can take the point on the surface of the supporting wall $O$.

The effectiveness of the boring process is largely dependent on the strength of the support frame. When working in hard soils of III-IV category, as well as in intermittent 
rocks with solid inclusions, various kinds of locks, tacking of the executive destructive organ of the auger are possible. If, at the same time, the jacking unit continues to feed of the rig on face, the equipment may go into an unstable skew state. This leads not only to a change in the specified direction of boring, but also to failure of the support and running units of the equipment. Boring horizontal and slightly deviated holes is possible in direct and reverse course.

The feed force and the reaction of the face are directed coaxially, however, the distance between the lines of their action is large, which leads to the state of the so-called unstable equilibrium, when even a slight bending deformation can lead to loss of stability of the equipment. In this case, the forces $F$ and $R$ will be directed at an angle to the horizontal and their further increase will contribute to the separation of the support frame from the surface, the destructive executive body to leave to the side and the loss of the specified direction of the hole axis.

KuzSTU's boring auger machines are structurally inherent in minimal misalignment of axial forces. The feed of equipment to the face is delivered along the guiding beams by hydraulic jacks pivotally attached to the carriage, the movable stoppers on their rods are made with the possibility of engagement with the fixed stepping stoppers with doubleacting wedge surfaces in the form of reverse "dovetails". The movable stoppers are kinematically coupled with self-adjusting lifting and lowering devices for the entire length of the direct or reverse step feed, which ensure locking engagement on any side of the fixed stepping stoppers on the modular frame during the carriage stroke. Since the resultant feed force $R$ lies on the axis of the rig, it can be argued that the forces $R$ and $F$ are coaxial. In addition, the distance from their lines of action is quite small (no more than the width of the transverse trench), which determines the state of stable equilibrium of the equipment.

From the above it follows that from the point of view of achieving a new technical level and from the point of view of configuration for specific indicators of boring accuracy and energy consumption, the most significant element in the designs of auger equipment developed at KuzSTU is a composite frame, the unified module of which is shown on fig. 2. It is along its guiding beams that the carriage with a boring machine, a sectional casing string, an auger stand placed in it, to which a tool for boring holes in direct or reverse course is connected.

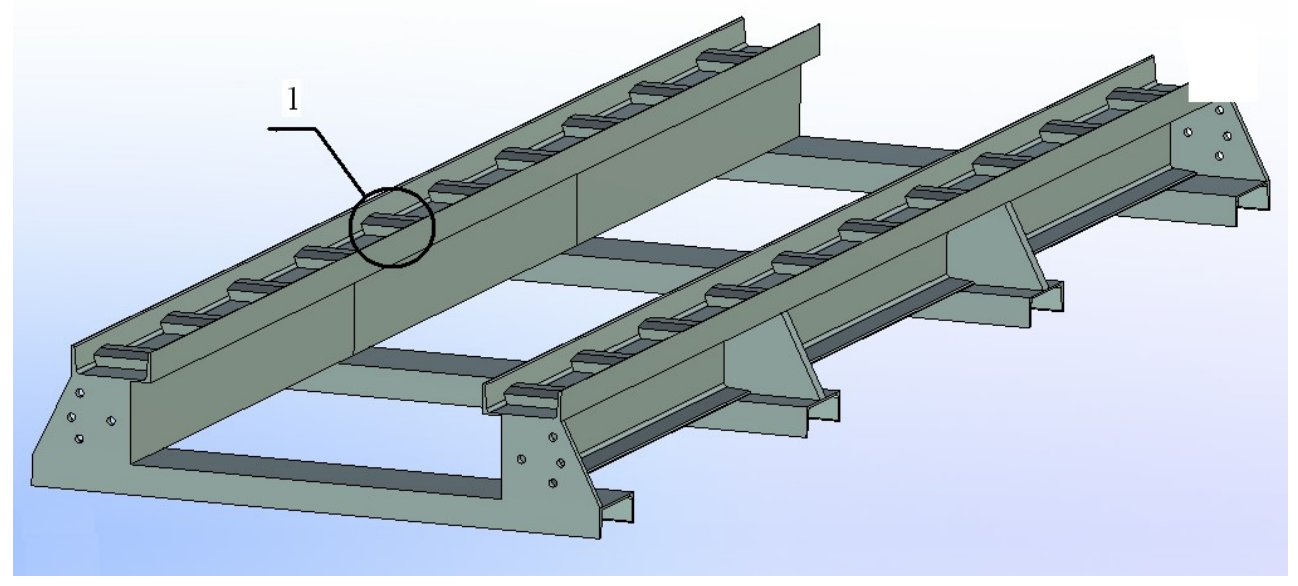

Fig. 2. The unified module of the sectional frame. Position 1 denotes one of the fixed stepping stoppers.

In this case, the fixed stepping stoppers alternately with each wedge surface are under the influence of the forces created by the hydraulic jacks for direct and reverse course, therefore, they are the most loaded structural elements. From the position of verification of 
the proposed technical solutions, it is precisely that the strength characteristics of the fixed stepping stoppers must be analyzed in the process of computer simulation.

\section{Results and discussion}

As indicated above, in the developed design, the operability of the guiding beams and the frame as a whole depends on the strength characteristics of the fixed stepping stoppers, their sizes, the geometric characteristics of their sections and the method of their connection with the beams. To verify the proposed technical solution on the model, it is necessary to assess the stress state of these stoppers under various external loading. Priority in the use in the analysis of the stress state of the structure is given to the finite element method (FEM), which is characterized by a proven mathematical algorithms, and the reliability of the results provided by modern computing capabilities. Fig. 3 shows the visualized results of stress state assessment.

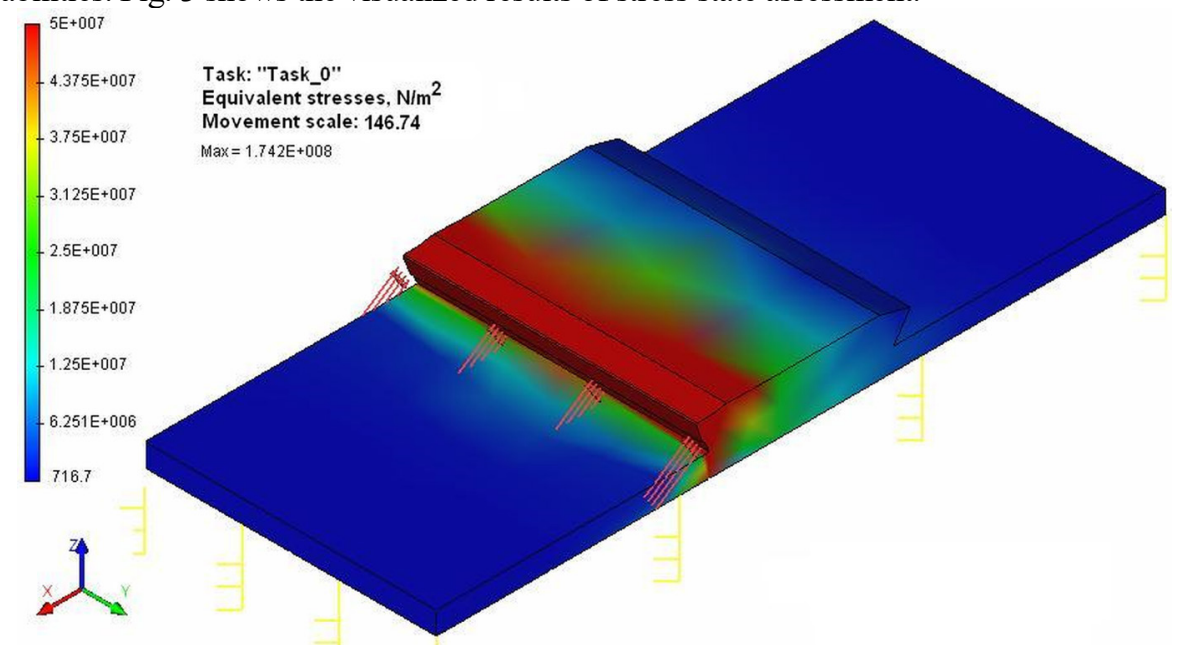

a
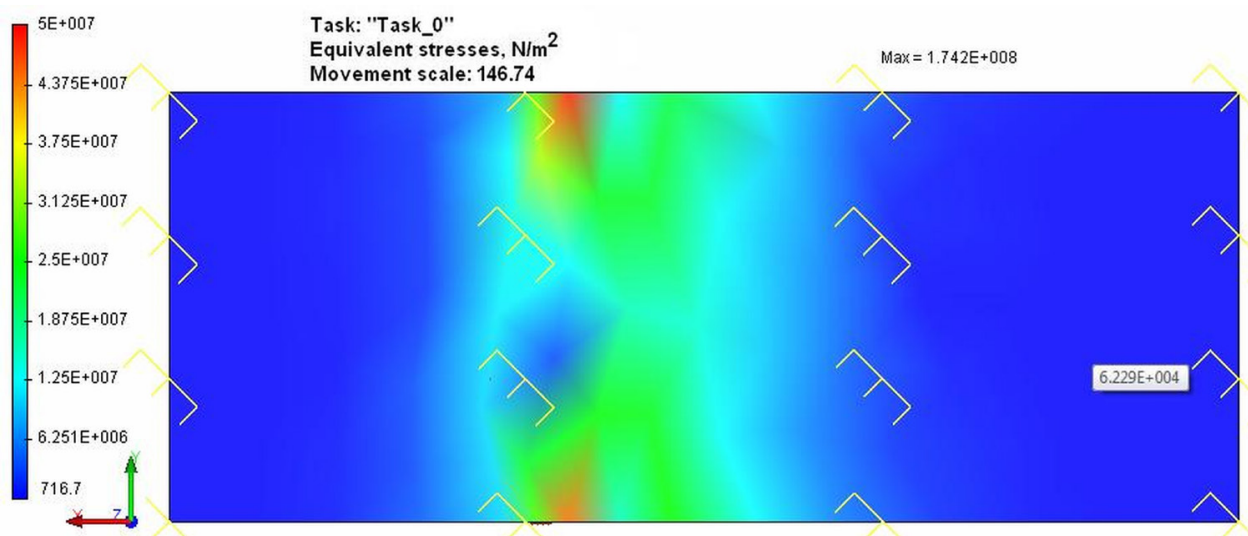

b

Fig. 3. Visualization of the stress state on the model of a fixed stepping stopper when applying a load of 20 ton: a - side view, $b$ - bottom view.

In the process of research the state of stress of the design of the stationary stepping stopper when changing the force of the hydraulic jack 5 ... 40 tons, stress concentration zones were identified. 
It is established that the manifestation of the stress concentration at the point of abutment of the stop with the surface of the guiding beam in places of application of external load increases as it grows. This fact provides the basis for a more thorough design study of the above connection, the choice of which depends on the performance of the sectional frame as a whole. For example, the rational use of slotted welds can be an effective step.

The used software allows for changes in the size and design of the stepping stoppers, and, possibly, of guide beams, followed by corrective modeling and re-verification. Fig. 4 shows the visualized results of modeling the stress state of the frame module as a whole.

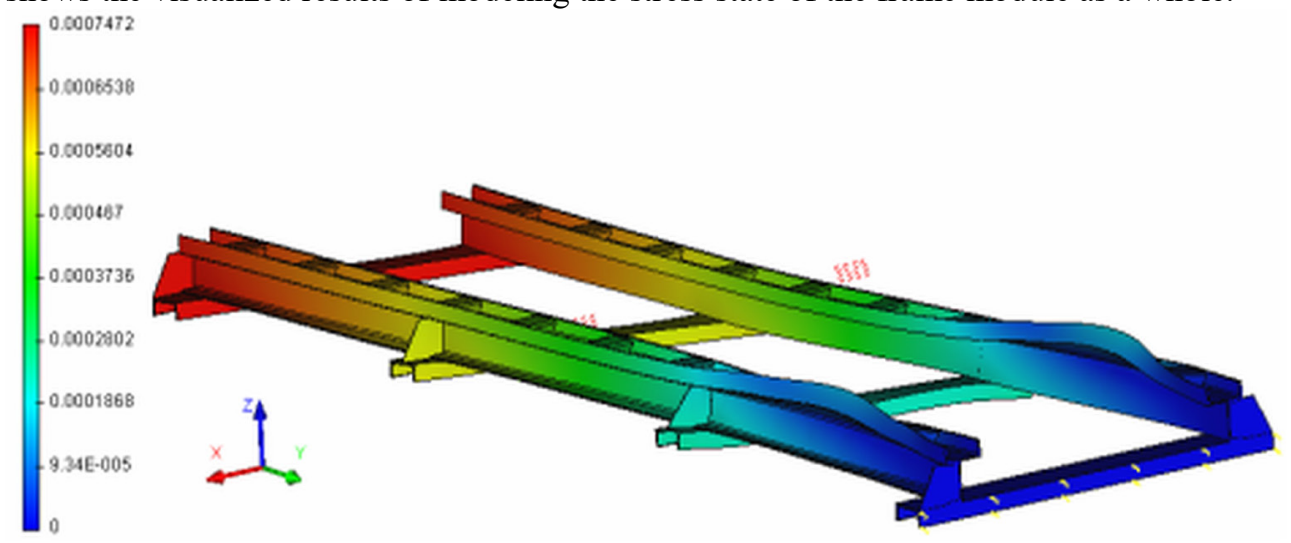

Fig. 4. Visualization of the stress state of the frame module as a whole.

The obtained results allowed ultimately to identify the advantages and disadvantages of the design of an open modular frame type with stoppers for fixing the machine unit, and to outline further ways to improve it as a whole.

\section{Conclusion}

The results can be used both for modernization of the existing design of thrust elements, and for the development of new technical solutions aimed at improving the operational reliability of the system for cyclic feeding of a machine unit of an auger complex to face when implementing the technology of two-stage boring of horizontal holes in a wide range of lengths and diameters.

Possible combinations of structural elements, loading schemes, fastening schemes of the supporting-guide subsystem are taken into account. Verification of the proposed technical solutions makes it possible to take into account the changes that are introduced, followed by corrective modeling and analysis, the results of which can be taken into account when developing auger complexes for sinking in specific soil or geological conditions.

\section{References}

1. R. Martin, B. Grolewski, NASTT No Dig Show, 1 (2011)

2. Pat. US 1604896 (1926)

3. Dictionary Geotechnical Engineering (Springer, Berlin, 2014)

4. R. Kanterman, Fire Eng., 151, 11 (1998)

5. V. Aksenov, V. Sadovets, D. Pashkov, E3S Web Conf., 21, 03011 (2017) 
6. V. Aksenov, A. Efremenkov, V. Sadovets, D. Pashkov, IOP Conf. Ser.: Mat. Sc. Eng., 012005 (2018)

7. V. Aksenov, V. Sadovets, D. Pashkov, E3S Web Conf., 105, 02009 (2018)

8. B. Danilov, Journ. of Min. Sc., 43 (2007)

9. V. Oparin, B. Danilov, B. Smolyanitski, Journ. of Min. Sc., 46 (2010)

10. B. Danilov, B. Smolyanitski, Journ. of Min. Sc., 49 (2013)

11. A. Gilev, V. Butkin, V. Chesnokov, Rus. Min., 6 (2003)

12. A. Shigin, A. Shigina, A. Gilev, S. Vokhmin, G. Kurchin, Journ. of Theor. and Appl. Inf. Technol, 80, 1 (2015)

13. K. Bovin, A. Gilev, A. Shigin, V. Chesnokov, A. Shigina, Journ. of Mech. Eng. and Technol., 10 (2019)

14. L. Mametyev, O. Lyubimov, Yu. Drozdenko, 8th Rus.-Chin. Symp. Adv. Eng. Res., 92 (2016)

15. L. Mametyev, O. Lyubimov, Yu. Drozdenko, Journ. of Min. Sc., 53, 2 (2017)

16. L. Mametyev, O. Lyubimov, Yu. Drozdenko, MATEC Web Conf., 297, 03003 (2019)

17. S. Kostyuk, N. Bedarev, O. Lyubimov, A. Shaikhislamov, E3S Web Conf., 21, 01002 (2017) 